\title{
Effects of Long-Term Hepatic Ischemia-Reperfusion Injury on the Function of P-glycoprotein in vivo in Rats
}

\author{
Camilla A. Thorling ${ }^{1,2}$, Michael S Roberts ${ }^{1,2}$, Xin Liu ${ }^{1}$, Linda M. Fletcher ${ }^{1,3}$ Darrell Crawford $^{1} \&$ Frank J. Burczynski ${ }^{4}$ \\ ${ }^{1}$ School of Medicine, The University of Queensland, Wolloongabba, Australia; ${ }^{2}$ School of Pharmacy and Medical Sciences, \\ University of South Australia, Adelaide, Australia; ${ }^{3}$ Department of Gastroenterology and Hepatology, Princess Alexandra \\ Hospital, Woolloongabba, Australia; and ${ }^{4}$ Faculty of Pharmacy, University of Manitoba, Winnipeg, Canada
}

Received, October 24, 2013; Revised, February 19, 2014; Accepted, February 28, 2014; Published, March 13, 2014.

\begin{abstract}
PURPOSE: Ischemia-reperfusion injury is a common complication in liver surgery with oxidative stress related graft failure as a potential complication. The oxidative stress could affect hepatic drug transporters such as P-glycoprotein, which is crucial in the hepatic clearance of certain immunosuppressant drugs. Thus,, it is important to study its function after ischemia-reperfusion injury in vivo. Rhodamine 123 is a fluorescent substrate of P-glycoprotein and its hepatic disposition can be visualized using multiphoton microscopy in vivo using anaesthetized animals. The aim of this study was to investigate the effect of long-term ischemia-reperfusion injury on P-glycoprotein function in hepatocytes using in vivo multiphoton microscopy. METHODS: Localized ischemia was induced for 1 hour in rats. The liver was reperfused for 4, 24, 48 hours or 1 week, where-after rhodamine 123 was injected intravenously. Multiphoton microscopy imaged the liver and bile was collected continuously up to 6 hours following drug administration. The liver was harvested for histology andprotein expression of Pglycoprotein. RESULTS: Ischemia-reperfusion injury resulted in extensive liver damage, inflammatory cell infiltration and apoptosis in the midzonal and centrilobular regions of the liver acinus. P-glycoprotein protein expression decreased. Cellular concentration of rhodamine 123 increased as visualized by multiphoton microscopy, which was confirmed with decreased excretion of rhodamine 123 in collected bile. CONCLUSIONS: This study showed reduced function of P-glycoprotein in ischemia-reperfusion injury as reflected by decreased biliary excretion of Rhodamine 123, as well as reduced protein expression of the transporter. Multiphoton microscopy could be used to visualize and quantitate the intracellular levels of rhodamine 123 . These findings stipulate the importance of using multiphoton microscopy to understand transmembrane drug flux and reflect on careful drug dosing after hepatic surgery.
\end{abstract}

This article is open to POST-PUBLICATION REVIEW. Registered readers (see "For Readers") may comment by clicking on ABSTRACT on the issue's contents page.

\section{INTRODUCTION}

Ischemia-reperfusion (I/R) injury is a common occurrence in liver surgery (e.g. liver transplantation and hepatic resection) where it is a major cause of morbidity and mortality $(1,2)$. In liver transplantation, the damage caused by ischemia is intensified when the transplanted liver is reperfused with blood (3). Reperfusion allows reintroduction of oxygenated blood resulting in oxidative stress, which causes increased microvascular permeability, intracellular ATP loss, inflammatory cell infiltration and potentially cell death (4-6). Oxidative stress could also lead to graft failure and rejection of the transplanted liver (7). The liver acinus is divided into three zones, where zone 1 is localized around the portal tract, zone 3 around the hepatic venules and zone 2 is in the midsection in between zone 1 and zone 3. Cells in zone 1 are exposed to high concentrations of oxygen and nutrients, whereas the blood reaching zone 3 has a lower concentration of these substrates (8). Investigations of $I / R$ injury in different zones in the liver are limited. Our group has shown predominant damage in zone 2 and 3 in early ischemia reperfusion injury (9). Cellular changes in $\mathrm{I} / \mathrm{R}$ injury have been shown to affect membrane proteins (10-12), which could lead to changes in drug distribution. In this study we explore the long-term effect of $\mathrm{I} / \mathrm{R}$ injury on the liver acinus.

\footnotetext{
Corresponding Author: Dr. Frank Burczynski, Faculty of Pharmacy, The University of Manitoba, Winnipeg, Manitoba, Canada. Email: burczyn@cc.umanitoba.ca
} 
Rhodamine 123 ( Rh123) is a cationic fluorescent dye and substrate of P-glycoprotein (Pgp) (13), an ATP-dependent efflux transporter (14) widely expressed in the bile canalicular membrane of hepatocytes, intestinal epithelium, renal proximal tubules (15) and capillary endothelial cells of the brain (16). Since Pgp plays a critical role on hepatic disposition of immunosuppressant drugs such as cyclosporine A and tacrolimus (17), it is of importance to understand its function in I/R injury.

Limited studies have investigated protein expression of transporters on I/R injury $(11,12,18$, 19), however, only one recent paper has investigated the function of Pgp by examining the biliary excretion pattern of Rh123 in the isolated perfused rat liver (20). Our study adds to these reports by utilizing multiphoton microscopy (MPM) to visualize the change in intracellular drug concentration of Rh123 in space and time in vivo following $\mathrm{I} / \mathrm{R}$ injury.

Multiphoton microscopy (MPM) enables high resolution imaging of physiology, morphology as well as cell-cell interactions in live animals and intact tissues through fluorescence intensity imaging (21). In order to excite an electron from a fluorescent molecule, two or more low energy photons are absorbed simultaneously $(22,23)$. The photons absorbed have similar energies and produce excitation equivalent to single photon absorption possessing twice the energy (21). MPM allows for non-invasive imaging of fluorescent molecules in biological tissues and has been widely used in neuroscience (24), cancer research (25), immunology (26) and ophthalmology (27). However, data showing the usefulness of MPM in studying hepatic drug distribution is limited, particularly in the injured liver. We previously used MPM to follow the metabolism of fluorescein (28, 29) and disposition of rhodamine 123 (Rh123) in normal rat liver in vivo (30). The aim of the present study was to investigate the function of Pgp using in vivo MPM in anaesthetized rats in combination with bile excretion data and plasma concentration as well as protein expression of Rh123 in the liver.

\section{METHODS}

\section{Chemicals and Reagents}

Rhodamine 123 was purchased from Sigma Aldrich (St Louis, MO). Ketamin hydrochloride (anesthesia) and Ilium Xylazil-20 (analgesic, sedative and muscle relaxant) were obtained from Parnell laboratories, Australia, and Bayer Australia (Pymble NSW, Australia), respectively. Reagents used for Western blot analysis were purchased from Thermo Fisher (Supersensitive West Femto Maximum Sensitivity, Pierce BCA Protein Assay Kit, Dental Developer replenisher, Dental fixer replenisher and T-mat $g$ film); Whatman (Whatman filter paper) and Bio-rad (Protein std precision plus BIO-Rad, IMMuno-blot membrane PVDF, $10 \times$ TGS Buffer, $10 \times$ TG Buffer, 30\% Acrylamide/Bis Solution, 29:1, TEMED and Ammonium Persulfate). P-glycoprotein monoclonal antibody (JSB-1; Catalogue number AB3366) was purchased from Sapphire Bioscience (Sydney NSW, Australia). The secondary antibody, Peroxidase AffiniPure Goat Anti-Mouse $\operatorname{IgG}(\mathrm{H}+\mathrm{L})$ (min X $\mathrm{Hu}, \mathrm{Bov}, \mathrm{Hrs}, \mathrm{Rb}, \mathrm{Sw} \mathrm{Sr}$ Prot), was purchased from Jackson ImmunoResearch Laboratories, Inc, (West Grove, PA, USA).

\section{Animals}

Male Wistar rats, weighting $300 \pm 30$ grams, purchased from the Animal Resource Centre (Perth, WA, Australia), were used in all experiments. Principles of laboratory animal care (NIH publication no. 85-23, revised 1985) were followed. In addition, all studies were approved by the Animal Ethics Committee of the University of Queensland. Rats were housed in the Biological Resource Facility at the Princess Alexandra Hospital, where the temperature was maintained at $20 \pm 1^{\circ} \mathrm{C}$ and humidity at $60-75 \%$, with artificial light for $12 \mathrm{~h} \mathrm{(7} \mathrm{am} \mathrm{to} 7$ pm) daily. All animals had unlimited access to food and water.

\section{Surgical procedures and I/R model}

Rats were anesthetized initially by an intraperitoneal injection of xylazil $(10 \mathrm{mg} / \mathrm{kg})$ and ketamine hydrochloride $(80 \mathrm{mg} / \mathrm{kg})$. Body temperature was controlled by placing rats on a heating pad set to $37^{\circ} \mathrm{C}$. A small midline laparotomy, using sterile surgery equipment, was performed to expose the liver. Sterile cotton tips were used to separate the lobes and to localize the portal vein, hepatic, artery and bile duct, supplying the median and left lobes of the liver. These vessels were then clamped using a microvascular clamp, causing approximately $70 \%$ ischemia. The rat was closely monitored and anesthesia was maintained throughout the experiment by administering maintenance doses of ketamine $(2.2 \mathrm{mg} / 100 \mathrm{~g})$ and xylazil $(0.25 \mathrm{mg} / 100 \mathrm{~g})$. 
The clamp was removed after $60 \mathrm{~min}$ to allow reperfusion of the liver for $4,24,48 \mathrm{~h}$ or 1 week. The wound was sutured, muscle and skin separately, using sterile silk suture. During the reperfusion rats were allowed to recover with close monitoring. Rats were given $0.02-0.05 \mathrm{mg} / \mathrm{kg}$ of Temgesic ${ }^{\circledR}$ (Pro vet PTY LTD, Reckitt Benckiser, NSW, Australia) immediately before awakening for pain relief. Sham operated rats (controls) underwent the same procedure without clamping the vessels and the reperfusion phase was set to 24 hours to minimize the number of rats in the study, but to account for any possible damage resulting from the surgery. At specific times of reperfusion rats were again anaesthetized. The jugular vein was cleared of surrounding tissue and cannulated using PE-tubing for administration of Rh123. A midline laparotomy was performed, the bile duct exposed and cleared of surrounding fat tissue and cannulated using PE10tubing for collection of bile. The left lobe of the liver was exposed for multiphoton imaging of Rh123 distribution. The liver and intraperitoneal cavity were kept moist by administering $0.9 \%$ saline continuously throughout the experiment. Rh123, dissolved in water $(4 \mathrm{mg} / \mathrm{kg})$, was injected intravenously at the time of reperfusion, i.e. 4, 24, 48 $\mathrm{h}$ or 1 week after induction of ischemia. Bile was collected in pre-weighted tubes every $10 \mathrm{~min}$ for 1 hour and every hour after that for 6 hours. MPM images were taken continuously throughout the experiment.

\section{Mulitphoton Microscopy (MPM)}

MPM images were taken using a DermaInspect system (JenLab GmbH, Jena, Germany) equipped with an ultrashort (85 femtosecond pulse width) pulsed mode-locked $80-\mathrm{MHz}$ Titanium:Sapphire MaiTai laser (Spectra Physics, 25 Mountain View, USA). The excitation wavelength was set to $740 \mathrm{~nm}$ for liver autofluorescence and $900 \mathrm{~nm}$ for Rh123 fluorescence, with an emission range of 350-650 $\mathrm{nm}$. The laser power was set to $15 \mathrm{~mW}$ and the acquisition time for obtaining the images was $13.4 \mathrm{~s}$ per frame. The left lobe of the liver was placed on a small metal plate, attached to an adjustable stand that could be elevated or lowered as required. The plate was slightly raised above the intraperitoneal cavity to minimize pressure on the organs underneath and to reduce movement in the image from respiration.

\section{Image processing}

Images were processed in ImageJ $1.44 p$ (National Institutes of Health, USA). Hepatocytes (approximately 10) were randomly selected and the fluorescence intensity was calculated. A standard curve was prepared in livers from control rats, without any treatment. The liver was homogenized in phosphate buffered saline (pH 7.4) 1:10. Rh123 was added to the liver homogenate at $0.25,0.50,1.0$, 2.04 .0 and $7.8 \mu \mathrm{g} / \mathrm{ml}$ and fluorescence intensity was measured using MPM and ImageJ. The intensity from hepatocytes was converted into concentrations using the standard curve prepared in homogenized liver.

\section{Tissue collection}

Blood $(0.2 \mathrm{~mL})$ was collected in lithium heparin tubes at the time of reperfusion from the inferior vena cava using a 30 gauge needle. At the end of the experiment, the left and median lobes were excised, portions were either snap frozen in liquid nitrogen and stored at $-70^{\circ} \mathrm{C}$ for later analysis with Western Blot or immersed into $10 \%$ buffered formalin for histological assessment.

\section{Serum biochemical measurements}

Plasma concentration of alanine aminotransferase (ALT) was measured using a Hitachi 747 analyzer (Hitachi Ltd., Tokyo, Japan).

\section{High-Performance Liquid Chromatography (HPLC)}

The concentration of Rh123 in each collected bile sample was determined by HPLC analysis using a Luna C18 column $(4.6 \times 150 \mathrm{~mm}, 5 \mu \mathrm{m})$ with fluorescence detector. Excitation and emission wavelengths were 470 and $580 \mathrm{~nm}$, respectively. The

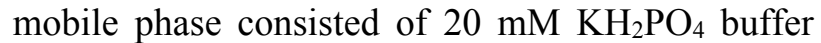
and acetonitrile $(3: 2, \mathrm{v} / \mathrm{v})$ and was delivered at 1 $\mathrm{mL} / \mathrm{min}$. A standard solution of Rh123 was prepared in water and the calibration curve was linear within the range of $0.15-5 \mu \mathrm{g} / \mathrm{ml}$. Each bile sample was diluted (1:10) with $0.2 \mathrm{mM}$ acetate buffer and incubated for 1 hour. Samples were then further diluted in water (1:11). An aliquot of the solution (10 $\mu \mathrm{L}$ ) was injected into the HPLC system (Shimadzu, Kyoto, Japan).

\section{Histopathological analysis}

Fixed liver was sub-sectioned onto each slide (2-3 sections at $5 \mu \mathrm{m}$ from different parts of each liver), 
stained, and scanned using an Aperio ScanScope XT slide scanning system (Aperio Technologies Inc., Vista, California, USA) at x20 magnification. Aperio ImageScope V10.2 software was used to visualize and score the slides. Staining of ApopTag (for apoptosis) and immunohistochemistry for ED1 (for macrophages/monocytes) was performed according to standard procedure. Visualization of ApopTag and ED1 localization was simplified with diaminobenzidine hydrochloride, which stained brown in positively-labeled cells. The number of monocytes and macrophages were identified by counting ED1-positive cells in the sinusoids in ten random fields per slide. Numbers of apoptotic cells were identified enzymatically using ApopTag labeling, and positive nuclei were counted in ten random fields per region per liver slide per zone of the liver. Zones identified were periportal, centrilobular, and midzonal.

\section{Western Blot}

Liver slices were homogenized (1:20; weight:volume) in protein lysis buffer solution, triton added $(10 \mu \mathrm{L} / \mathrm{ml}$ buffer $)$ and samples stored on ice. The solution was centrifuged at $13,000 \mathrm{rpm}$ at $4^{\circ} \mathrm{C}$ for $20 \mathrm{~min}$ and the supernatant collected. The supernatant, equivalent to $50 \mu \mathrm{g}$ of protein, was mixed with loading buffer and heated for $5 \mathrm{~min}$ at $100^{\circ} \mathrm{C}$. A $7.5 \%$ acrylamide resolving gel and $4 \%$ stacking gel, both with SDS, were prepared with Tris-glycine as running buffer. Samples were electrophoresed at $150 \mathrm{~V}$ for $45 \mathrm{~min}$ and blotted onto polyvinyl fluoride membrane at $100 \mathrm{~V}$ for 1 hour at $4^{\circ} \mathrm{C}$. The membrane was blocked in $10 \%$ skim milk in blocking buffer (tris-buffered saline with $0.1 \%$ Tween $20=$ TBS-T) overnight at $4^{\circ} \mathrm{C}$ with shaking. The membrane was incubated with Pgp antibody,
1:100 dilution in blocking buffer for $1.5 \mathrm{~h}$ and then washed with TBS-T. Following incubation with the secondary antibody at 1:5000 dilution for $1.5 \mathrm{~h}$, the membrane was washed in TBS-T first and then TBS. The membrane was developed onto film using luminescence kit (SuperSignal ${ }^{\circledR}$ West Femto) reacting for $5 \mathrm{~min}$. $\beta$-actin was used as a housekeeping gene with primary antibody dilution at $1: 1000$, and secondary antibody dilution at $1: 200,000$. Protein bands were quantified using Image J and Pgp image results adjusted for the loading density bands of $\beta$-actin.

\section{STATISTICAL ANALYSIS}

An unpaired, parametric t-test with Welch's correction was used. Results were considered significant with a $p$-value $\leq 0.05$.

\section{RESULTS}

\section{Alanine aminotransferase (ALT) levels}

ALT significantly increased at $4 \mathrm{~h}(1350 \pm 262 \mathrm{U} / \mathrm{L})$ and $24 \mathrm{~h}(736 \pm 202 \mathrm{U} / \mathrm{L})$ compared to sham $(44.3 \pm$ $3.79 \mathrm{U} / \mathrm{L})(\mathrm{p} \leq 0.05)$. Values returned to normal levels after at $48 \mathrm{~h}(97.7 \pm 20.5 \mathrm{U} / \mathrm{L})$ and 1 week $(51.3 \pm$ $9.20 \mathrm{U} / \mathrm{L}$ ) of reperfusion (Table 1). The early increased ALT level indicated extensive liver damage caused by $\mathrm{I} / \mathrm{R}$ injury.

\section{Histopathology}

Inflammatory cell infiltration (monocytes and macrophages) was statistically higher after $24 \mathrm{~h}$ (285 $\pm 26.2)$ of reperfusion compared to sham (172 \pm 14.2) $(\mathrm{n}=4, \mathrm{p}<0.05)$. Following 1 week of reperfusion, the number of inflammatory cells was similar to sham $(151 \pm 38.9)$ (Table 1$)$.

\begin{tabular}{lcc}
\hline \multicolumn{2}{l}{ Table 1. Alanine transaminase (ALT) levels in plasma and inflammatory cells (monocytes/macrophages) in the liver } \\
after I/R injury at different reperfusion time points. ALT was significantly increased at 4 and 24 h, whereas \\
inflammatory cells were significantly increased at 24 h of reperfusion (values \pm SEM, ${ }^{*}$ p $<0.05, \mathrm{n}=4$ ). \\
\hline Group & ALT (U/L) & Number of inflammatory cells \\
Sham & $44.3 \pm 3.79$ & $172 \pm 14.2$ \\
$4 \mathrm{~h}$ & $1350 \pm 262^{*}$ & $288 \pm 69.5$ \\
$24 \mathrm{~h}$ & $736 \pm 202^{*}$ & $285 \pm 26.2^{*}$ \\
$48 \mathrm{~h}$ & $97.7 \pm 20.5$ & $391 \pm 84.7$ \\
1 week & $51.3 \pm 9.20$ & $151 \pm 38.9$ \\
\hline
\end{tabular}


Apoptotic cells were stained by ApopTag and counted in each of three different zones of the liver acinus (periportal, centrilobular and midzonal) that were randomly selected (Figure 1, Table 2). Black arrows indicate DNA damaged cells. The number of positively stained cells was significantly higher in the centrilobular region at $4 \mathrm{~h}(43.2 \pm 12.8)$ of reperfusion compared to sham $(6.00 \pm 1.47)$ and in the midzonal region at $4(112 \pm 18.2)$ and $24 \mathrm{~h}(56.8$ $\pm 5.74)$ and decreased in the midzonal region after 1 week of reperfusion $(6.25 \pm 2.39)(\mathrm{p} \leq 0.05)$ compared to sham $(14.0 \pm 1.08)$. No significant difference of apoptotic cell numbers was found in the periportal region.

\section{Periportal}
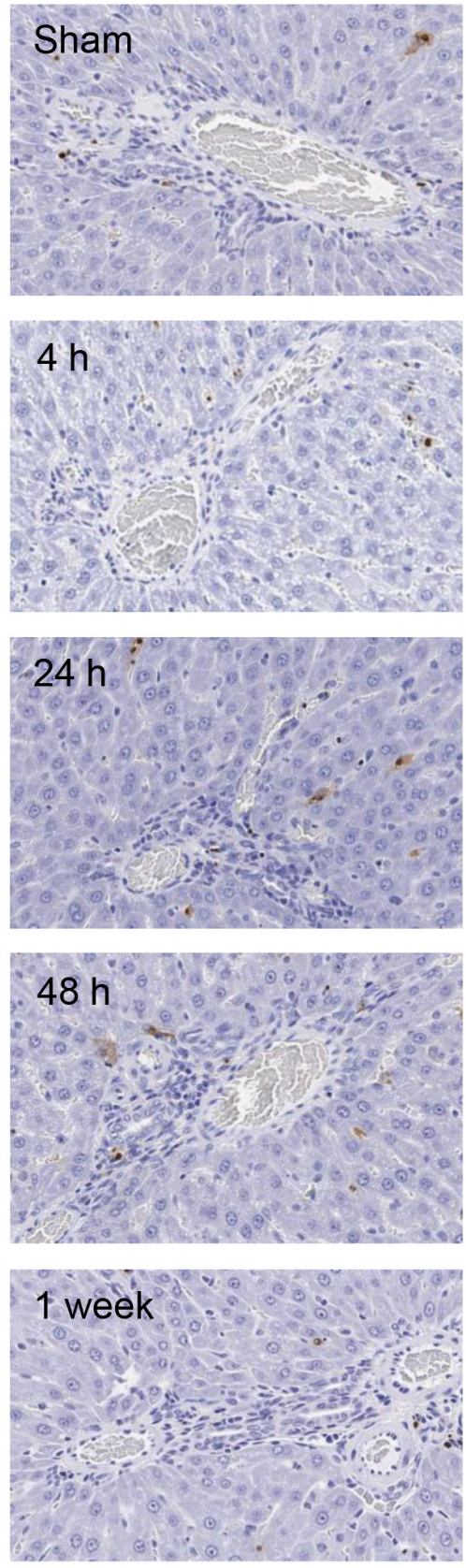

\section{Centrilobular}
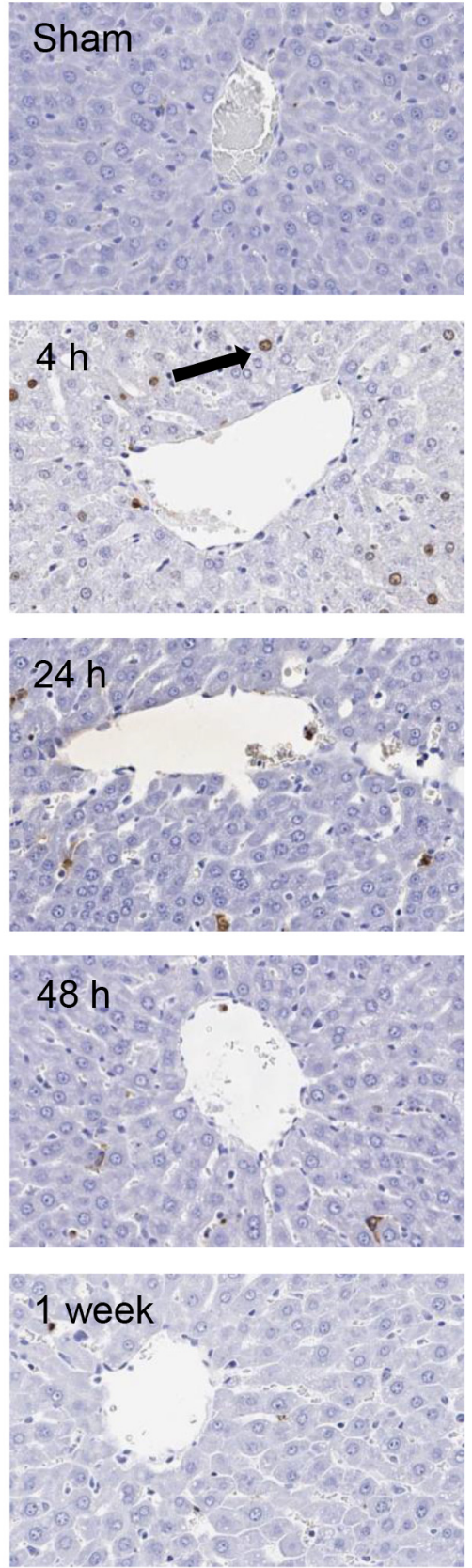

\section{Midzonal}
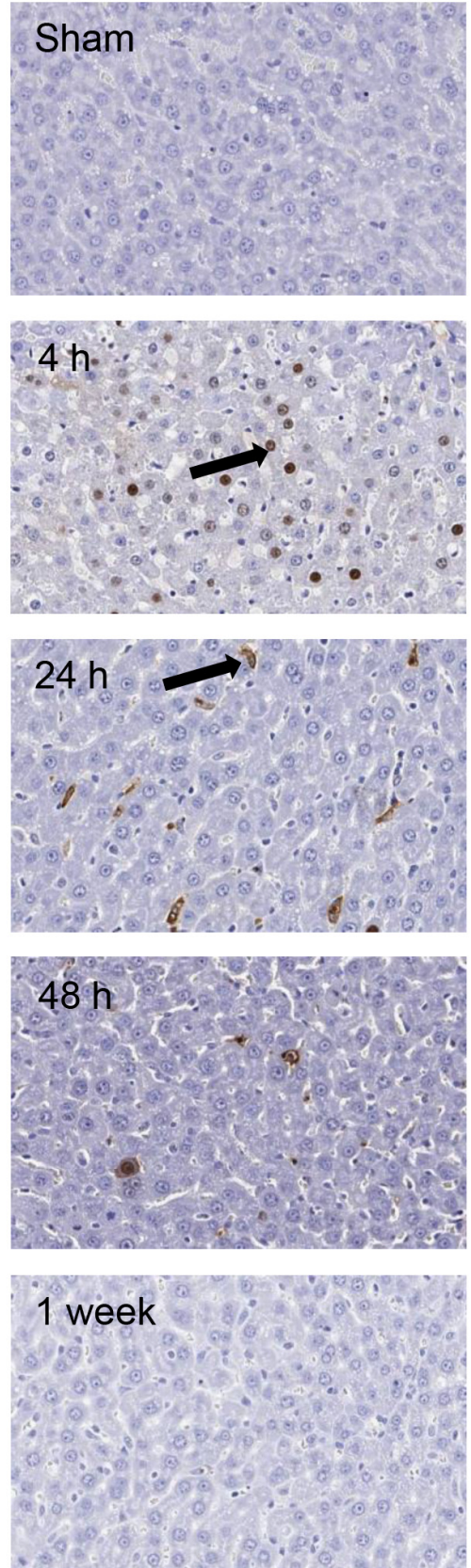

Figure 1. Apoptotic cells. Positively stained apoptotic cells, in the three regions of the liver acinus, periportal, centrilobular and midzonal, were counted in 10 random fields per slide. Black arrows indicate Apoptag-positive cells. 


\section{I/R induced changes to Pgp transporter expression}

Pgp level was measured by Western blot (Figure 2).

Protein levels decreased significantly at $48 \mathrm{~h}(0.357$

$\pm 0.155)$ of reperfusion compared to sham $(1.36 \pm$

$0.274)(\mathrm{n}=4, \mathrm{p}<0.05$; Figure $2 \mathrm{~A})$. As shown in Figure

$2 \mathrm{~A}$, the decrease in protein levels compared to sham were $52 \%, 48 \%$ and $74 \%$ at $4 \mathrm{~h}, 24 \mathrm{~h}$ and $48 \mathrm{~h}$, respectively. Expression of Pgp returned to near initial levels after 1 week $(1.32 \pm 0.194)$, where the percentage value was $3 \%$ lower than sham. The corresponding protein-bands for Pgp and $\beta$-actin are shown in Figure 2B.

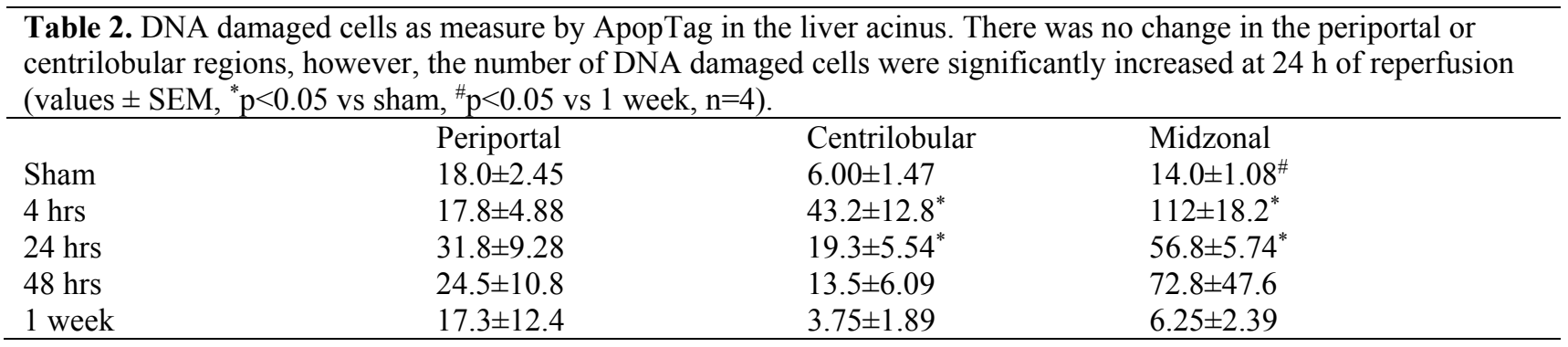

a)

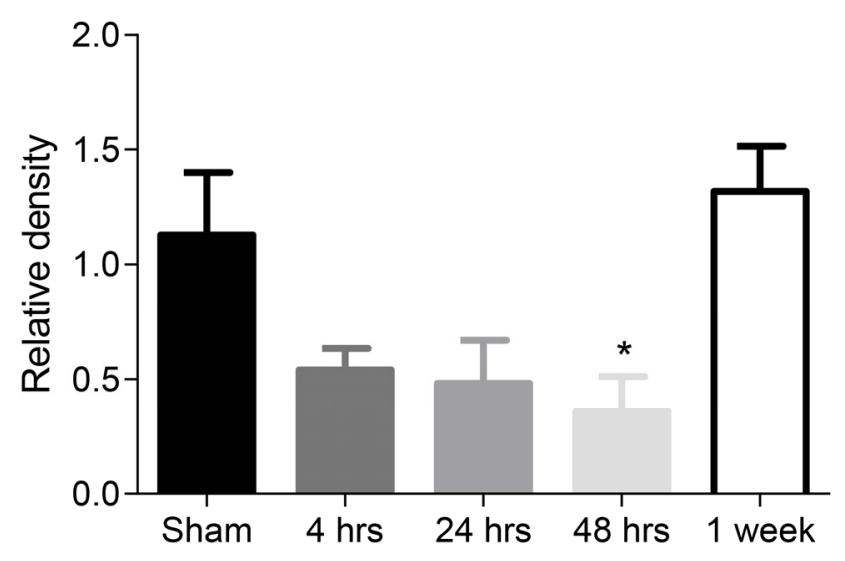

b)

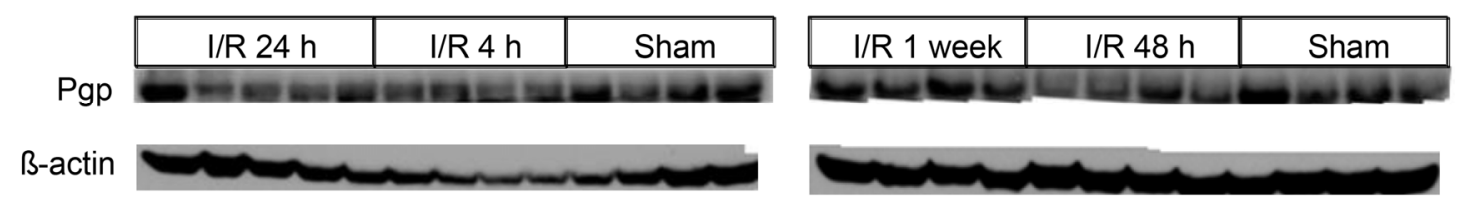

Figure 2. Protein expression of P-glycoprotein. Protein expression (a) of the transporter (Pgp) involved in the excretion of Rh123 within the rat liver of sham and I/R injury groups (4, 24, $48 \mathrm{~h}$ and 1 week). (b) Western blots of Pgp and $\beta$-actin expression from four independent rats in sham and I/R injury groups $(4,24,48 \mathrm{~h}$ and 1 week of reperfusion). Values are presented as the mean $\pm \operatorname{SEM}(n=4),{ }^{*} \mathrm{p}<0.05$ significantly different from sham.

\section{Rh123 uptake and excretion in I/R damaged liver} The individual bile flow rates for the first $60 \mathrm{~min}$ post-injection in all reperfusion groups are shown in Figure 3A-D. The bile flow rates were statistically decreased in the $4 \mathrm{~h}$ reperfusion group (Figure $3 \mathrm{~A}$ ) compared to sham $(\mathrm{p}<0.05)$. Area under the curve (AUC) was calculated for each individual rat and the average value, representing the total amount of bile 
excreted after $60 \mathrm{~min}$, is shown in Figure 3E. Biliary excretion rates and cumulative excretion amount of Rh123 recovered in bile are shown in Figure 4. The biliary excretion rate of Rh123 was statistically reduced in the $4 \mathrm{~h}$ reperfusion group, when compared
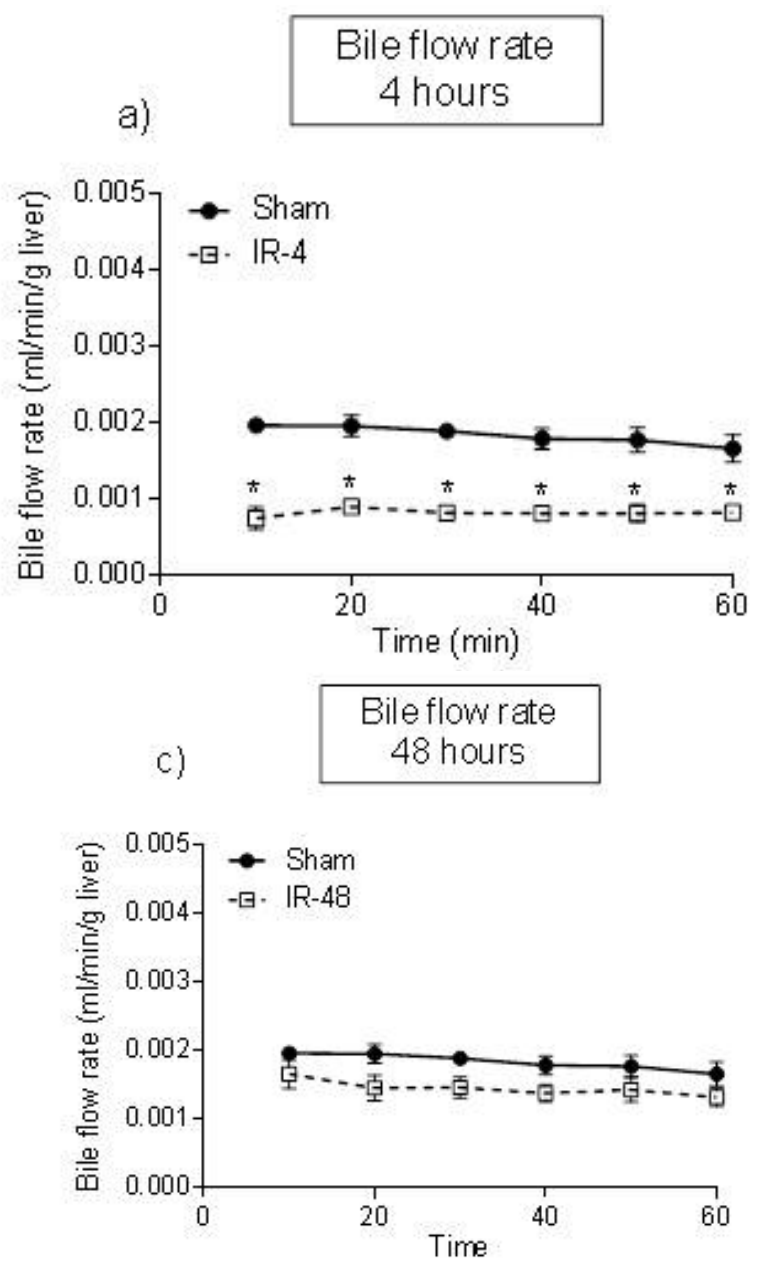

to the sham group (Figure 4A). The area under the biliary excretion rate curve (AUC), representing the total amount of $\mathrm{Rh} 123$ excreted after $60 \mathrm{~min}$, decreased significantly at $4 \mathrm{~h}$ of reperfusion $(\mathrm{p}<0.05$; Figure 4E).
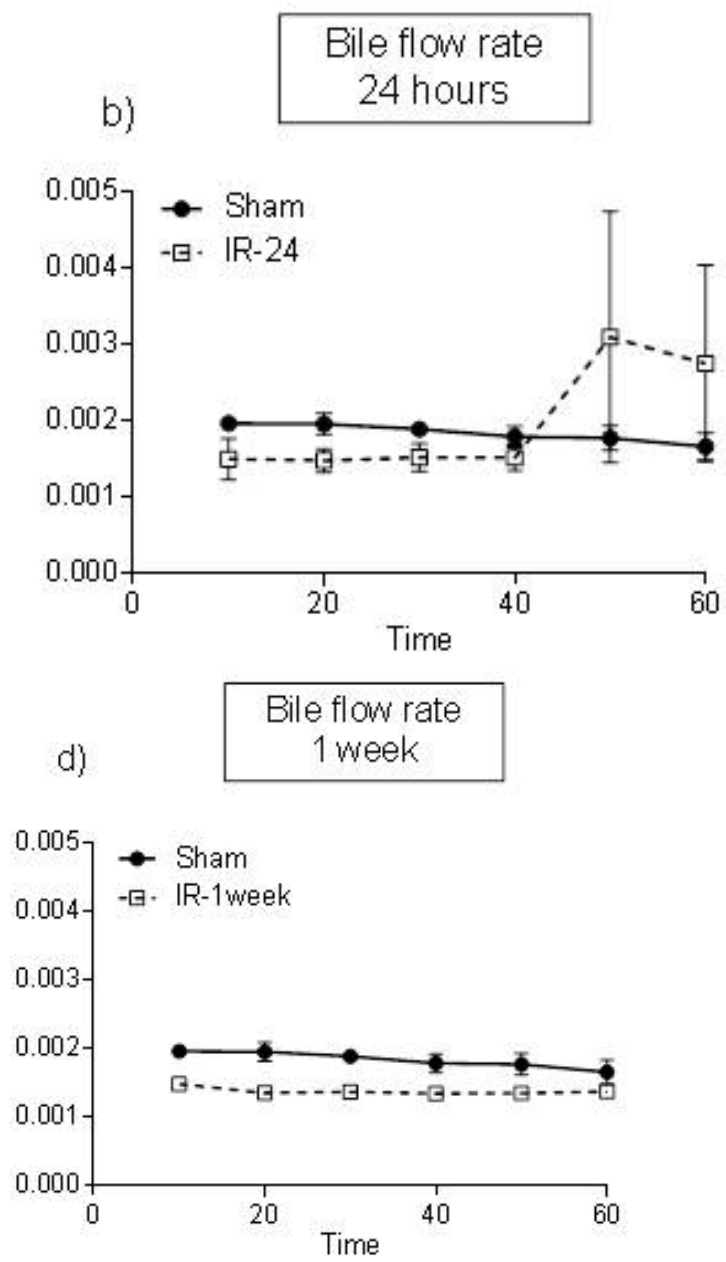

e) bile excreted

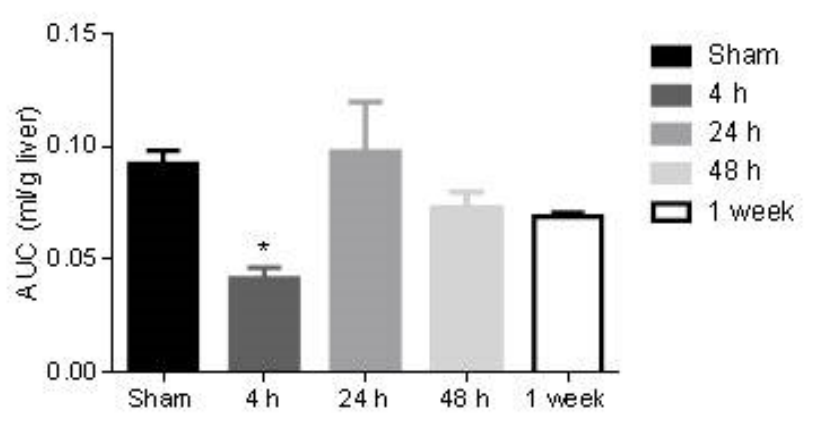

Figure 3. Bile flow rate of Rhodamine 123. Bile flow rate of Rh123 after a) 4 h, b) 24 h, c) 48 h, and d) 1 week of reperfusion. e) The total amount of bile excreted after the first 60 min post injection \pm SEM, $(n=4)$. Values are presented as the mean \pm $\operatorname{SEM}(\mathrm{n}=4),{ }^{*} \mathrm{p}<0.05$ significantly different from sham. 

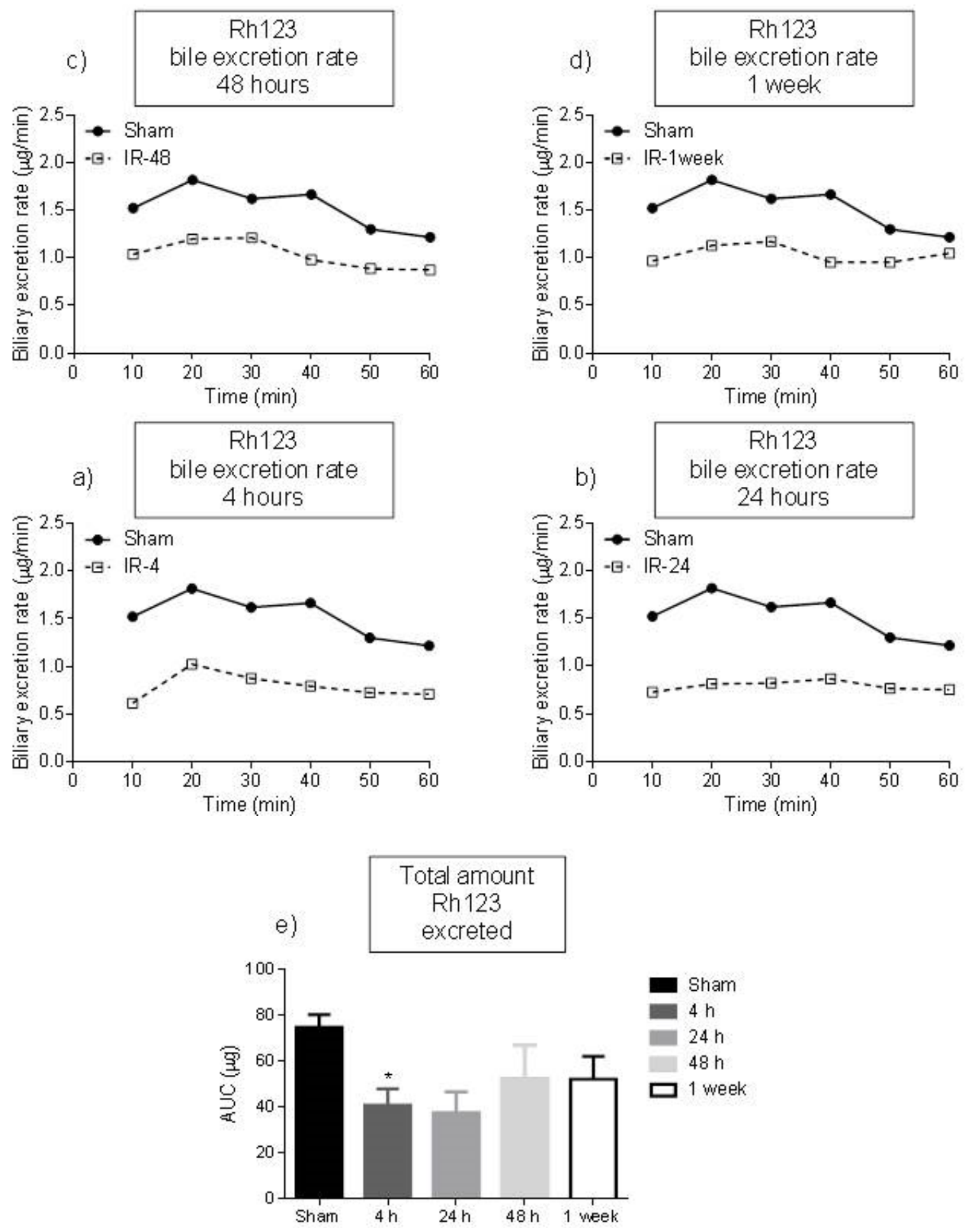

Figure 4. Biliary excretion rate of Rhodamine 123. Biliary excretion rate of Rh123 after a) 4 h, b) 24 h, c) 48 h and d) 1 week of reperfusion. e) Total amount of Rh123 excreted in the bile after 60 min. Values are presented as the mean $\pm \operatorname{SEM}(\mathrm{n}=4)$, * $\mathrm{p}<0.05$ significantly different from sham.

MPM images of sham and $\mathrm{I} / \mathrm{R}$ damaged liver were continuously recorded in vivo after bolus injection of Rh123 to monitor differences in uptake and clearance of the dye. As shown in a representative imaged liver (Figure 5), Rh123 fluorescence intensity was higher for all $\mathrm{I} / \mathrm{R}$ groups 
at all time points and Rh123 fluorescence took longer to diminish compared to sham. Fluorescence intensity for the 1 week $\mathrm{I} / \mathrm{R}$ group diminished faster than that for the other I/R groups, however, it was still greater than the sham group. The intensity of Rh123 in hepatocytes was converted into concentrations using a standard curve prepared in homogenized liver. Accumulation of Rh123 in hepatocytes was determined by calculating AUC of concentrations versus time profiles (Figure 6). The results show significantly increased accumulation of $\mathrm{Rh} 123$ in the hepatocytes at $24 \mathrm{~h}$ of reperfusion in the I/R injury group compared to sham. The $48 \mathrm{hr}$ time point was also higher but did not reach statistical significance $(\mathrm{p}=0.07)$. The AUC at 1 week showed a decline in values, consistent with an increase in Pgp levels (Figure 2).

\section{DISCUSSION}

The present study aims to investigate the function of Pgp in long-term I/R injury using in vivo MPM in combination with traditional in vitro techniques such as HPLC to study biliary excretion and Western blot that was used to evaluate transporter level. In addition, histopathological analyses were performed to evaluate inflammatory cell infiltration and apoptosis.
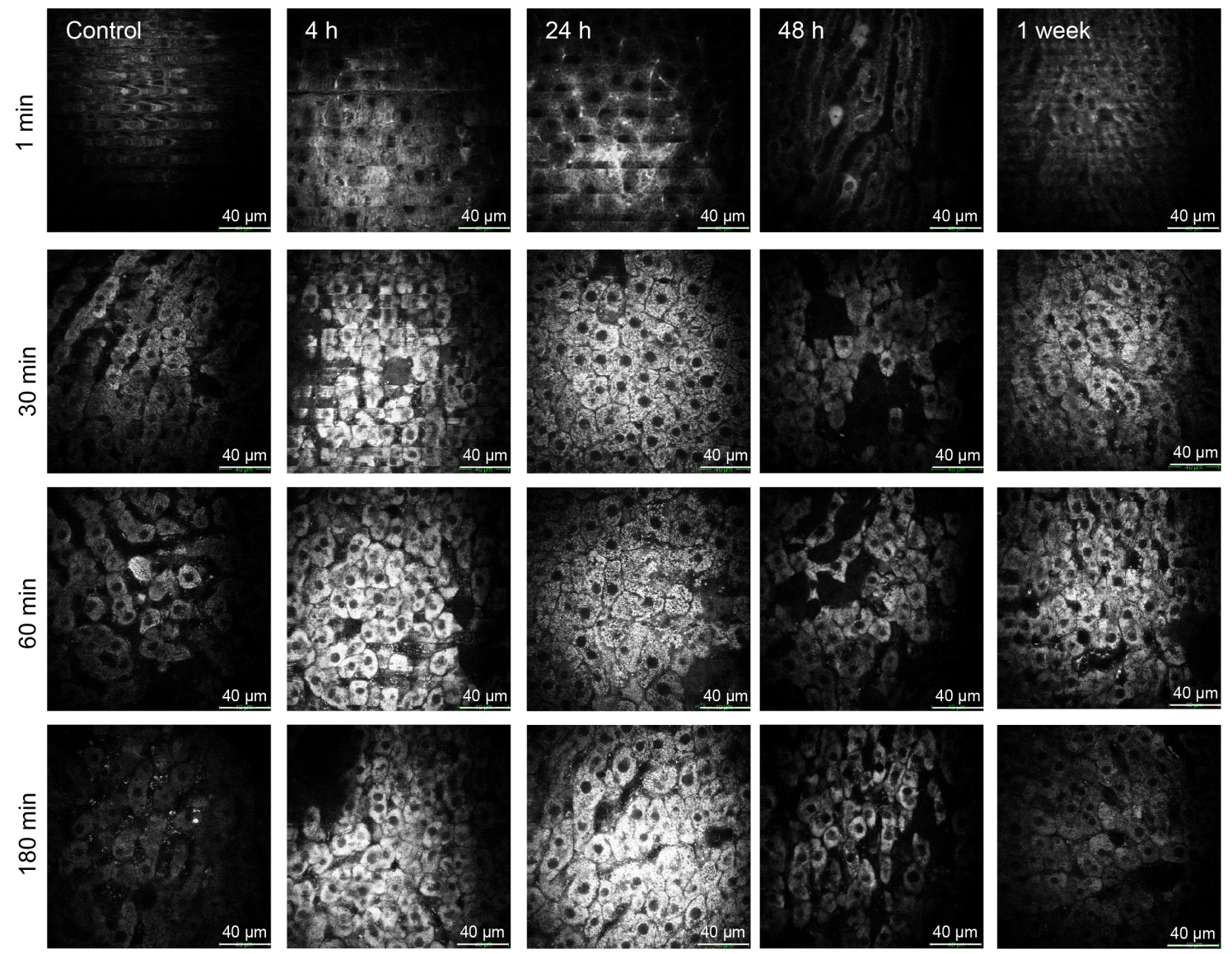

Figure 5. Multiphoton microscopy showing Rhodamine 123 distribution in the liver. Representative MPM images of Rh123 distribution in sham and I/R injury at 4, 24, $48 \mathrm{~h}$ and 1 week of reperfusion. Fluorescence intensity images were recorded in vivo at $900 \mathrm{~nm}$ excitation wavelength for sham and I/R injury groups at various time points using high (X40) magnifications. Scale bar indicate a length $40 \mu \mathrm{m}$. 

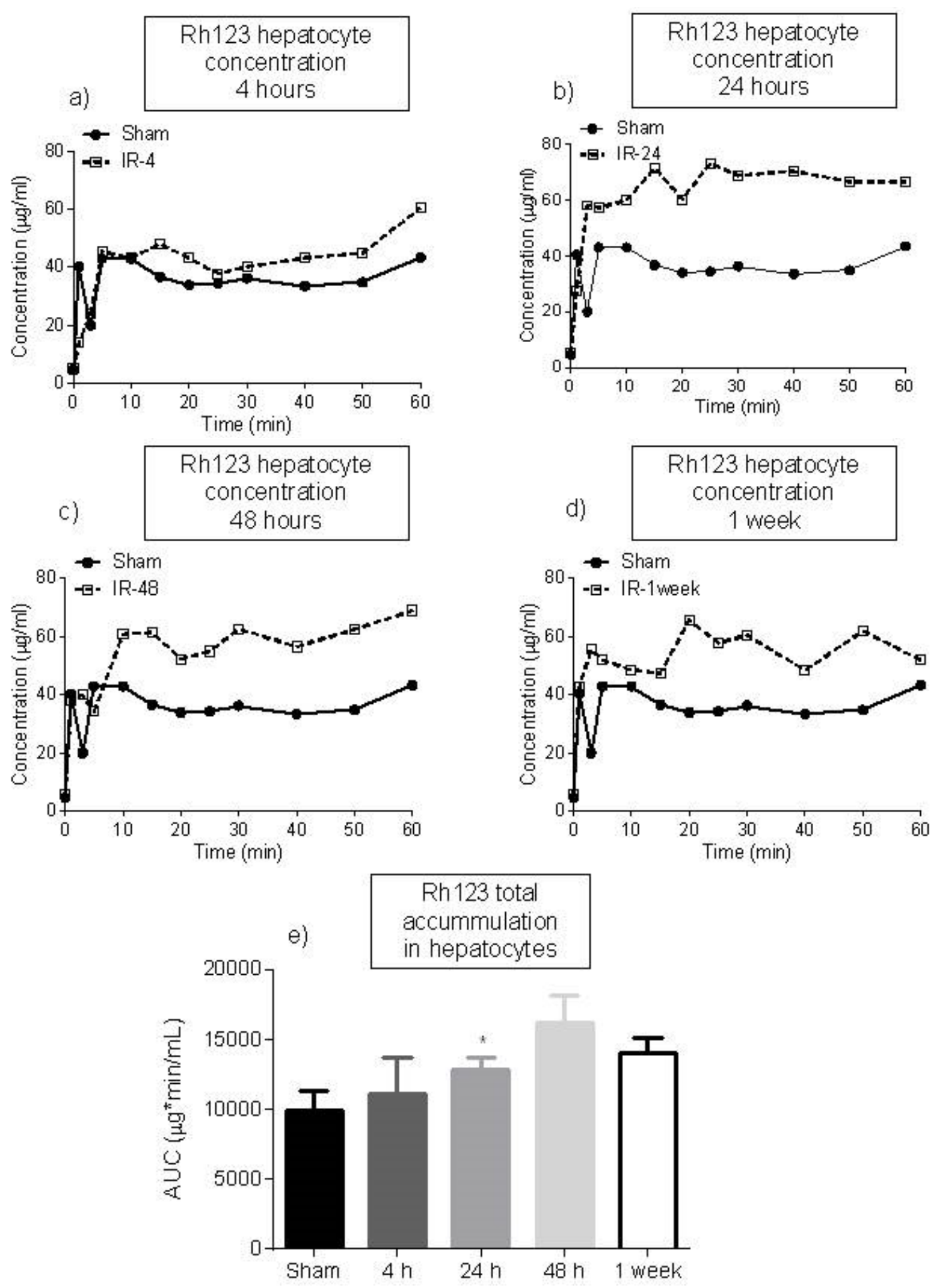

Figure 6. Concentration of Rhodamine 123 in the hepatocytes. Change in Rh123 concentration over time within hepatocytes, measured by multiphoton microscopy in hepatic I/R injury at a) 4, b) 24, c) $48 \mathrm{~h}$ and d) 1 week compared to sham. A standard curve of Rh123 fluorescence intensity to concentration was established to measure unknown concentrations by multiphoton microscopy. Rh123 accumulation (area under the curve, AUC) was calculated from Rh123 fluorescence intensity changes within the hepatocytes. Values are presented as the mean \pm SEM $(n=3-4)$. 
It is well known that $\mathrm{I} / \mathrm{R}$ injury is divided into two phases. The early phase (up to $2 \mathrm{~h}$ ) is characterised by activation of Kupffer cells and free radical formation, with the late phase $(4-24 \mathrm{~h})$ reflecting accumulation of neutrophils and more free radical formation (31). In this study we report a significant increase in monocytes/macrophages in liver of rats with $\mathrm{I} / \mathrm{R}$ injury at 24 and $48 \mathrm{~h}$ reperfusion, which returned to baseline values after 1 week. The number of monocytes/macrophages early in I/R injury has previously only been studied following $4 \mathrm{~h}$ of reperfusion (9) with an increase in neutrophils reported at 6-24 h of reperfusion (32). The increased number of macrophages/monocytes could be a response to inflammatory signals, e.g. interferon- $\gamma$ and tumor necrosis factor $(33,34)$. In addition, macrophages could also proliferate locally, called alternatively activated macrophages induced by interleukin 4 (IL-4) (35). Macrophage proliferation in response to IL-4 has been shown in Kupffer cells $(35,36)$.

In addition to the inflammatory signal response, liver damage also can be assessed by the number of apoptotic cells. In the present study there was a significant increase in apoptotic cells in the centrilobular and midzonal regions at 4 and $24 \mathrm{~h}$ (Figure 1, Table 2), which confirmed a heterogenous spread of liver damage as previously reported (9). Positive ApopTag staining of the liver seen in Figure 1 may be indicative of cells undergoing repair or apoptosis (37), as the DNA is stained in the damaged nuclei of affected cells (38). In addition, significantly increased levels of ALT were seen at 4 and $24 \mathrm{~h}$, indicating extensive liver damage caused by $I / R$ injury. This coincides with previous published data $(39,40)$, and suggests that the ApopTag staining was indicative of apoptosis rather than repair. A comprehensive study of cellular damage in longterm hepatic I/R injury prior to the present study has to our knowledge not been reported. Zonal spread of damage in different liver diseases, however, has been shown. For example, in alcohol induced liver injury, hypoxia and free radical production were shown to affect the centrilobular region (41), whereas in cancer and cirrhosis the midzonal region was more susceptible to oxidative stress (42). In addition, the centrilobular and midzonal regions were the most affected following acetaminophen administration (43).

It is reasonable to say that the cellular changes in $\mathrm{I} / \mathrm{R}$ injury must impact transporters located in cell membranes, which play a critical role in drug disposition (44). Thus, it is important to study the function of transporters in liver disease in order to predict the hepatic and biliary/intestinal exposure of drugs and metabolites (45). A limited number of reports describe hepatic transporter function in $I / R$ injury $(10-12,19)$, with a main focus on protein and mRNA expression of the transporters. The function of the transporters, with respect to uptake and excretion of drugs in intact anesthetized animals, however, not been investigated. Results show a substantial reduction in Pgp expression at 4, 24 and $48 \mathrm{~h}$ reperfusion, which reached statistical significance at $48 \mathrm{~h}$ (Figure 2A). I/R injury is known to be associated with a reduction in other drug transporters $(11,12,19)$. For example, Ntcp, Mrp2 and Bsep were markedly reduced in studies using cultured hepatocytes (11) and a similar reduction was seen for Mrp2 in liver homogenates after 24 and 48 $\mathrm{h}$ of reperfusion (19). Also, our group reported decreased protein expression of Mrp3 in I/R injury (46). In addition, protein expression of Pgp was measured in intestinal $\mathrm{I} / \mathrm{R}$ injury, where it was significantly decreased after 1 and $3 \mathrm{~h}$ of reperfusion compared to control $(17,47)$. mRNA expression of mdr1a and mdrlb was not significantly decreased (data not shown).

The bile flow rate was significantly decreased at $4 \mathrm{~h}$ of repefusion $(\mathrm{p}<0.05)$, with statistical improvement at $24 \mathrm{~h}$ to 1 week. This coincided with another study of hepatic I/R injury, where the bile flow rate was $30 \%$ lower in the I/R group compared to sham (48). In addition, another study of I/R injury reported significantly decreased bile flow at $24 \mathrm{~h}$, which returned to normal values at $72 \mathrm{~h} \mathrm{(20).} \mathrm{It} \mathrm{is}$ possible that the decreased bile flow is a result of impaired microcirculation in the liver. I/R injury has previously been described to decreased sinusoidal density, hence impair hepatic microcirculation (49, $50)$. As a consequence, biliary excretion rate of Rh123 was significantly decreased at $4 \mathrm{~h}$ of reperfusion $(p<0.05)$. A reduced biliary excretion rate as well as decreased recovery of Rh123 was previously reported in $\mathrm{I} / \mathrm{R}$ injury at $24 \mathrm{~h}$ of reperfusion $(20,48)$. The reduced biliary excretion rate found in our study may also be a consequence of posttranscriptional regulation or factors such as Pgp in vivo half-life $(51,52)$. A recent study showed that the excretion of Rh123 was substantially reduced $(90 \%)$ in the presence of the Pgp inhibitor cyclosporine A (53). Moreover, our group showed 
significantly increased fluorescence of Rh123 in hepatocytes after cyclosporine A treatment (30).

Our work showed that I/R injury decreases the excretion of Rh123 and reduces the protein expression of Pgp. Thus, our next approach was in determining whether we were able to visualize the changes in vivo. Results showed significantly increased accumulation of Rh123 in the hepatocytes in I/R injury at $24 \mathrm{~h}$ of reperfusion. These results are in agreement with a recent study conducted by our group showing that Pgp inhibition by cyclosporine A increased the hepatocyte fluorescence of Rh123 (30). The decline in hepatocyte fluorescence was slower for the cyclosporine A pre-treated group than in control (30). In another recent study by our group, we showed that the transport of fluorescein was impaired in hepatic $I / R$ injury (46). The present results show that MPM can be used to study drug distribution and transporter function in liver injury models in vivo. It is beneficial to conventional drug distribution studies, such as the isolated perfused liver, in that it directly observes how concentrations of a drug change over time and in space in intact animals and is arguably a better model of understanding drug distribution (30). In addition, there is no artificial perturbation of hepatic blood flow. Drug is delivered to the liver via both the intact hepatic artery and portal vein. Moreover, MPM allows for simultaneous examination of cellular morphology in intact animals (21).

\section{CONCLUSIONS}

The present study confirmed that I/R injury caused heterogeneous spread of the damage across the liver acinus. Short term I/R injury $(4 \mathrm{~h})$ resulted in impaired biliary excretion of Rh123 as a result of reduced bile flow and decreased protein expression of Pgp. Multiphoton microscopy showed increased fluorescence intensity in hepatocytes in early I/R injury, which recovered after 1 week. The findings here stipulate that drugs excreted by P-glycoprotein could be affected after liver surgery and that care should be taken in drug dosing in these situations.

\section{ACKNOWLEDGEMENTS}

This study was made possible through support by National Health and Medical Research Council (NHMRC \#569710). We thank Mr Clay Winterford and colleagues at Queensland Institute of Medical
Research (QIMR) for preparing histology and immunohistochemistry, $\mathrm{Mr}$ Goce Dimeski and colleagues at Queensland Pathology Services, Princess Alexandra Hospital, for conducting ALT measurements and Mrs Lesley-Anne Jaskowski and Ms Erika de Guzman for technical assistance with Western Blot. Lastly, thanks to Dr Washington Jnr Sanchez for manuscript proof reading and expert opinions.

\section{ABBREVIATIONS}

$\mathrm{ALT}=$ alanine aminotransferase

HPLC $=$ high-performance liquid chromatography

$\mathrm{I} / \mathrm{R}=$ ischemia reperfusion

$\mathrm{MPM}=$ multiphoton microscopy

Pgp $=$ P-glycoprotein

Rh123 = rhodamine 123

\section{REFERENCES}

1. Takamatsu Y, Shimada K, Yamaguchi K, Kuroki S, Chijiiwa K, Tanaka M. Inhibition of inducible nitric oxide synthase prevents hepatic, but not pulmonary, injury following ischemiareperfusion of rat liver. Dig Dis Sci 2006;51:571-579.

2. Baumann J, Ghosh S, Szakmany T, Jancso G, Ferencz A, Roth E, Bogar L. Short-term effects of N-acetylcysteine and ischemic preconditioning in a canine model of hepatic ischemia-reperfusion injury. Eur Surg Res 2008;41:226-230.

3. Hart ML, Much C, Kohler D, Schittenhelm J, Gorzolla IC, Stahl GL, Eltzschig HK. Use of a hanging-weight system for liver ischemic preconditioning in mice. Am J Physiol Gastrointest Liver Physiol 2008;294:G14311440.

4. Chavez-Cartaya R, Jamieson NV, Ramirez P, Marin J, Pino-Chavez G. Free radical scavengers to prevent reperfusion injury following experimental warm liver ischaemia. Is there a real physiological benefit? Transpl Int 1999; 12:213-221.

5. Sener G, Tosun O, Sehirli AO, Kacmaz A, Arbak S, Ersoy Y, Ayanoglu-Dulger G. Melatonin and $\mathrm{N}$-acetylcysteine have beneficial effects during hepatic ischemia and reperfusion. Life Sci 2003;72:2707-2718. 
6. Crenesse D, Gugenheim J, Hornoy J, Tornieri K, Laurens M, Cambien B, Lenegrate G, Cursio R, De SG, Auberger P, Heurteaux C, Rossi B, Schmid-Alliana A. Protein kinase activation by warm and cold hypoxia- reoxygenation in primary-cultured rat hepatocytesJNK(1)/SAPK(1) involvement in apoptosis. Hepatology 2000;32:1029-1036.

7. Sasaki $H$, Matsuno $T$, Ishikawa $T$, Ishine $N$, Sadamori H, Yagi T, Tanaka N. Activation of apoptosis during early phase of reperfusion after liver transplantation. Transplant Proc 1997;29:406-407.

8. Sherman IA, Fisher MM. Hepatic transport of fluorescent molecules: in vivo studies using intravital TV microscopy. Hepatology 1986;6:444-449.

9. Thorling CA, Liu X, Burczynski FJ, Fletcher LM, Gobe GC, Roberts MS. Multiphoton microscopy can visualize zonal damage and decreased cellular metabolic activity in hepatic ischemia-reperfusion injury in rats. J Biomed Opt 2011;16:116011.

10. Ban D, Kudo A, Sui S, Tanaka S, Nakamura N, Ito K, Suematsu M, Arii S. Decreased Mrp2dependent bile flow in the post-warm ischemic rat liver. J Surg Res 2009;153:310-316.

11. Fouassier L, Beaussier M, Schiffer E, Rey C, Barbu V, Mergey M, Wendum D, Callard P, Scoazec JY, Lasnier E, Stieger B, Lienhart A, Housset C. Hypoxia-induced changes in the expression of rat hepatobiliary transporter genes. Am J Physiol Gastrointest Liver Physiol 2007;293:G25-35.

12. Tanaka Y, Chen C, Maher JM, Klaassen CD. Kupffer cell-mediated downregulation of hepatic transporter expression in rat hepatic ischemia-reperfusion. Transplantation 2006;82:258.

13. Huls M, Russel FG, Masereeuw R. The role of ATP binding cassette transporters in tissue defense and organ regeneration. J Pharmacol Exp Ther 2009;328:3-9.

14. Sharom FJ. The P-glycoprotein efflux pump: how does it transport drugs? J Membr Biol 1997;160:161-175.

15. Thiebaut F, Tsuruo T, Hamada H, Gottesman MM, Pastan I, Willingham MC. Cellular localization of the multidrug-resistance gene product P-glycoprotein in normal human tissues. Proc Natl Acad Sci U S A 1987;84:7735-7738.
16. Huang ZH, Murakami T, Okochi A, Yumoyo R, Nagai J, Takano M. Expression and function of P-glycoprotein in rats with carbon tetrachlorideinduced acute hepatic failure. J Pharm Pharmacol 2001;53:873-881.

17. Tomita M, Takizawa Y, Kishimoto H, Hayashi M. Assessment of ileal epithelial P-glycoprotein dysfunction induced by ischemia/reperfusion using in vivo animal model. Drug Metab Pharmacokinet 2008;23:356-363.

18. Ikemura K, Urano K, Matsuda H, Mizutani H, Iwamoto T, Okuda M. Decreased oral absorption of cyclosporine A after liver ischemiareperfusion injury in rats: The contribution of CYP3A and P-glycoprotein to the first-pass metabolism in intestinal epithelial cells. Journal of Pharmacology and Experimental Therapeutics 2009;328:249.

19. Tanaka Y, Chen C, Maher JM, Klaassen CD. Ischemia-reperfusion of rat livers decreases liver and increases kidney multidrug resistance associated protein 2 (Mrp2). Toxicol Sci 2008;101:171-178.

20. Parasrampuria R, Shaik IH, Mehvar R. Effects of in vivo hepatic ischemia-reperfusion injury on the hepatobiliary disposition of rhodamine 123 and its metabolites in isolated perfused rat livers. J Pharm Pharm Sci 2012;15:318-328.

21. Zipfel WR, Williams RM, Webb WW. Nonlinear magic: multiphoton microscopy in the biosciences. Nat Biotechnol 2003;21:13691377.

22. Dunn KW, Young PA. Principles of multiphoton microscopy. Nephron Exp Nephrol 2006;103:e33-40.

23. Lee HS, Liu Y, Chen HC, Chiou LL, Huang GT, Lo W, Dong CY. Optical biopsy of liver fibrosis by use of multiphoton microscopy. Opt Lett 2004;29:2614-2616.

24. Rai S, Srivastava A, Sooriakumaran P, Tewari A. Advances in imaging the neurovascular bundle. Curr Opin Urol 2012;22:88-96.

25. Brown EB, Campbell RB, Tsuzuki Y, Xu L, Carmeliet P, Fukumura D, Jain RK. In vivo measurement of gene expression, angiogenesis and physiological function in tumors using multiphoton laser scanning microscopy. Nat Med 2001;7:864-868.

26. Ishii T, Ishii M. Intravital two-photon imaging: a versatile tool for dissecting the immune system. Ann Rheum Dis 2011;70 Suppl 1:1113-115. 
27. Gibson EA, Masihzadeh O, Lei TC, Ammar DA, Kahook MY. Multiphoton microscopy for ophthalmic imaging. J Ophthalmol 2011;2011:870879.

28. Roberts MS, Roberts MJ, Robertson TA, Sanchez W, Thorling C, Zou Y, Zhao X, Becker $\mathrm{W}, \mathrm{Zvyagin} \mathrm{AV}$. In vitro and in vivo imaging of xenobiotic transport in human skin and in the rat liver. J Biophotonics 2008;1:478-493.

29. Thorling CA, Dancik Y, Hupple CW, Medley G, Liu X, Zvyagin AV, Robertson TA, Burczynski FJ, Roberts MS. Multiphoton microscopy and fluorescence lifetime imaging provide a novel method in studying drug distribution and metabolism in the rat liver in vivo. J Biomed Opt 2011;16:086013.

30. Liu X, Thorling CA, Jin L, Roberts MS. Intravital multiphoton imagin of rhodamine 123 in the rat liver after intravenous dosing. IntraVital 2012;1:54-59.

31. Fusai G, Glantzounis GK, Hafez T, Yang W, Quaglia A, Sheth H, Kanoria S, Parkes H, Seifalian A, Davidson BR. N-Acetylcysteine ameliorates the late phase of liver ischaemia/reperfusion injury in the rabbit with hepatic steatosis. Clin Sci (Lond) 2005;109:465473.

32. Hisama N, Yamaguchi Y, Ishiko T, Miyanari N, Ichiguchi $\mathrm{O}$, Goto $\mathrm{M}$, Mori $\mathrm{K}$, Watanabe $\mathrm{K}$, Kawamura K, Tsurufuji S, Ogawa M. Kupffer cell production of cytokine-induced neutrophil chemoattractant following ischemia/reperfusion injury in rats. Hepatology 1996;24:1193-1198.

33. Randolph GJ. Immunology. No need to coax monocytes. Science 2011;332:1268-1269.

34. Mosser DM. The many faces of macrophage activation. J Leukoc Biol 2003;73:209-212.

35. Jenkins SJ, Ruckerl D, Cook PC, Jones LH, Finkelman FD, van RN, MacDonald AS, Allen JE. Local macrophage proliferation, rather than recruitment from the blood, is a signature of TH2 inflammation. Science 2011;332:1284-1288.

36. Milner JD, Orekov T, Ward JM, Cheng L, Torres-Velez F, Junttila I, Sun G, Buller M, Morris SC, Finkelman FD, Paul WE. Sustained IL-4 exposure leads to a novel pathway for hemophagocytosis, inflammation, and tissue macrophage accumulation. Blood 2010;116:2476-2483.

37. Hughes J, Gobe G. Identification and quantification of apoptosis in the kidney using morphology, biochemical and molecular markers. Nephrology (Carlton) 2007;12:452458.

38. Ormerod AD, Copeland P, Hay I, Husain A, Ewen SW. The inflammatory and cytotoxic effects of a nitric oxide releasing cream on normal skin. J Invest Dermatol 1999;113:392397.

39. Liu Z, Xu Z, Shen W, Li Y, Zhang J, Ye X. Effect of pharmacologic preconditioning with tetrandrine on subsequent ischemia/reperfusion injury in rat liver. World J Surg 2004;28:620624.

40. Matsui N, Kasajima K, Hada M, Nagata T, Senga N, Yasui Y, Fukuishi N, Akagi M. Inhibiton of NF-kappaB activation during ischemia reduces hepatic ischemia/reperfusion injury in rats. J Toxicol Sci 2005;30:103-110.

41. Maher JJ. Exploring alcohol's effects on liver function. Alcohol Health and Research World 1997;21:5-12.

42. Mouta CC, Nasser SM, di TE, Padera TP, Boucher Y, Tomarev SI, Jain RK. LYVE-1 is not restricted to the lymph vessels: expression in normal liver blood sinusoids and downregulation in human liver cancer and cirrhosis. Cancer Res 2001;61:8079-8084.

43. Lores AS, Llesuy S, Cutrin JC, Boveris A. Oxidative stress by acute acetaminophen administration in mouse liver. Free Radic Biol Med 1995;19:303-310.

44. Li FC, Liu Y, Huang GT, Chiou LL, Liang JH, Sun TL, Dong CY, Lee HS. In vivo dynamic metabolic imaging of obstructive cholestasis in mice. Am J Physiol Gastrointest Liver Physiol 2009;296:G1091-1097.

45. Li P, Wang GJ, Robertson TA, Roberts MS. Liver transporters in hepatic drug disposition: an update. Curr Drug Metab 2009;10:482-498.

46. Thorling CA, Liu X, Burczynski FJ, Fletcher LM, Roberts MS, Sanchez WY. Intravital multiphoton microscopy can model uptake and excretion of fluorescein in hepatic ischemia reperfusion injury. $\mathrm{J}$ Biomed $\mathrm{Opt}$ 2013; 18:101306.

47. Tomita M, Takizawa Y, Kishimoto H, Hayashi M. Effect of intestinal ischaemia/reperfusion on P-glycoprotein-mediated ileal excretion of rhodamine 123 in the rat. J Pharm Pharmacol 2009;61:1319-1324. 
48. Miah MK, Shaik IH, Bickel U, Mehvar R. Effects of Hepatic Ischemia-Reperfusion Injury on the P-Glycoprotein Activity at the Liver Canalicular Membrane and Blood-Brain Barrier Determined by In Vivo Administration of Rhodamine 123 in Rats. Pharm Res 2013:1-13.

49. Sun CK, Zhang XY, Zimmermann A, Davis G, Wheatley AM. Effect of ischemia-reperfusion injury on the microcirculation of the steatotic liver of the Zucker rat. Transplantation 2001;72:1625-1631.

50. Mendes-Braz M, Elias-Miró M, Jiménez-Castro M, Casillas-Ramírez A, Ramalho F, Peralta C. The Current State of Knowledge of Hepatic Ischemia-Reperfusion Injury Based on Its Study in Experimental Models. Journal of Biomedicine and Biotechnology 2012;2012:1-20.
51. Fu N, Drinnenberg I, Kelso J, Wu JR, Paabo S, Zeng R, Khaitovich P. Comparison of protein and mRNA expression evolution in humans and chimpanzees. PLoS One 2007;2:e216.

52. Nie L, Wu G, Zhang W. Correlation of mRNA expression and protein abundance affected by multiple sequence features related to translational efficiency in Desulfovibrio vulgaris: a quantitative analysis. Genetics 2006;174:2229-2243.

53. Parasrampuria R, Mehvar R. Effects of $P$ glycoprotein and Mrp2 inhibitors on the hepatobiliary disposition of Rhodamine 123 and its glucuronidated metabolite in isolated perfused rat livers. Journal of pharmaceutical sciences 2010;99:455-466. 